writing, which gives the commandments of the god, at the monthly and at the annual (?) sacrifices in order that it may be clear who abides by them and who does not. $O$ Saviour ZEus, hear our words, and give us a good requital, health, deliverance, peace, safety on land and sea.' (Italics added by author of article.)

To what extent Pythagorean elements may be traceable in the cult of AgDistis and the survival of such distinguishable elements as late as 100 B. c. may well be a subject for enquiry. The similarity of some of the wording of the ethical elements in the AgDistis inscription to those of the "Hippocratic" Oath are, in any event, self-evident. To read them will leave that document less isolated than it was before.

The Text of the Agdistis inscription is given in W. Dittenbergen's Sylloge Inscriptionum Graecarum, Edition 3, no 985. I have reproduced the translation of Professor A.D. Nock of Harvard from his work Conversion: The Old and the New in Religion from Alexander the Great to Augustine of Hippo, Oxford 1933, by whose permission and that of the Clarendon Press this is here printed. I am also grateful to my colleague, Professor V. G. Childe, for having drawn my attention to this passage.

\title{
On Galen's Pneumatology
}

\author{
By Owsei Temkin, Baltimore
}

As is well known, GaLen believed that the soul had three divisions to each of which a special anatomical seat could be allocated. He devoted his work On the dogmas of Hippocrates and Plato to the proof that the divine soul with which man thinks dwells in the brain, while passion (especially wrath) and desires have their principles in the heart and liver respectively. To this psychological division corresponds a physiological one. The brain

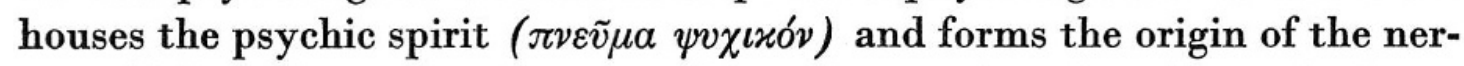
ves which conduct sensations as well as voluntary impulses. From the heart the arteries containing blood and vital spirit ( $\pi v \varepsilon \tilde{v} \mu \tilde{\alpha} \zeta \omega \tau \iota x o ́ v)$ depart, regulating the innate heat of the body and nourishing the psychic pneuma. The liver ist the main organ of hematopoiesis and also the origin of the veins which carry nourishment to the rest of the body. 
In its broad outlines, this sketch of the Galenic doctrine as far as the tripartite soul and its faculties are concerned, can be amply documented by references to some of GALEN's fundamental works. It is equally true that the terms "pneuma" in general and "psychic spirit" and "vital spirit" in particular are frequently used by GALEN. He may have accepted this terminology from Erasistratus who, as GaLen writes, "says that the psychic spirit proceeds from the brain, the vital spirit from the heart". ${ }^{1}$ As to the details of the sketch, they require many apmplifications and qualifications. We shall discuss a few of them here, taking our starting point from the question: did GALEN also assume the existence of a "natural spirit" ( $\pi v \varepsilon \tilde{v} \mu \alpha$ $v \sigma \sigma \varkappa o ́ v)$ as a well defined third kind of pneuma?

In their outlines of the Galenic system, most of our textbooks give conventional sanction to the "natural spirit". It is supposed to have its seat in liver and veins in analogy to the psychic spirit of brain and nerves, and the vital spirit of the heart and arteries. It is true, of course, that Greek medicine, especially of the pneumatic school, knew of a natural spirit. Thus the pseudo-Galenic Medical definitions speak of a natural spirit in veins and arteries ${ }^{2}$. But this work reflects a system, according to which there are three forms of spirit: "Hexis", "Physis", and "Soul". 3 This system was influenced by Stoic philosophy, and GALEN was neither a Stoic nor a follower of the so-called pneumatic school. As a matter of fact, some students of ancient pneumatology, e.g. VERBEKE ${ }^{4}$, do not mention the natural spirit at all in their discussion of Galen's views. Drabisin, on the other hand, has briefly stated that the natural spirit in liver and veins, though mentioned, had been "hardly incorporated into his system" by GALEN and that only later ages had made the system symmetrical ${ }^{5}$. With this statement I find myself in substantial agreement.

${ }^{1}$ De placitis Hippocratis et Platonis, rec. I. Mueller, vol. 1, Lipsiae 1874, p. 245, 10-3. On the pneumatology of Erasistratus cf. G. VerbeKe, L'évolution de la doctrine du pneuma du stö̈cisme à S. Augustin, Paris-Louvain 1945, p. 177-91.

${ }^{2}$ Definitiones medicae, nos. 73 and 74 (Galeni Opera omnia, ed. KüHN, vol. 19, p. 365). See also further below, note 33 .

${ }^{3}$ Cf. ibid., definitions 29, 95 and 96 (ed. KüHN, p. 355, 371 and 372). See also Verbeke, op. cit., p. $192 \mathrm{f}$. On the chronology and provenience from the pneumatic school of the Definitiones medicae see Max Wellmann, Die pneumatische Schule, Berlin 1895, p. $65 \mathrm{ff}$. The English reader will find a good discussion of the pneumatic views in Sir T. CLIFFord Allbutr's Greek medicine in Rome, London 1921, p. 224ff.

${ }^{4}$ See above, note 1.

${ }^{5}$ Morris R.Cohen and I.E.Drabkin, A Source Book in Greek Science, New York, McGraw-Hill Book Co., 1948, p. 486. 
In chapter 5 of book 12 of the Method of treatment, GALEN writes: "Concerning the psychic spirit, we have clearly shown that the brain is its fount, so to speak, and that it is watered and nourished by inspiration and by the supply from the rete mirabile. Concerning the vital spirit, the demonstration has not been equally clear, yet it does not seem unlikely that it is contained in the heart and the arteries and that it too is chiefly nourished by the respiration and also the blood. And if there also is a natural spirit, this again should be contained in the liver and the veins". ${ }^{6}$ I must admit that this is the only passage in GALEN's work definitely speaking of the natural spirit and its seat in liver and veins with which I am so far acquainted.

Now it seems remarkable that GaLeN expresses himself so cautiously not only about the natural spirit, but the vital spirit as well. Yet there are ample references in his writings where GALEN attaches no doubt to the existence of a vital spirit". He seems to connect it with the "inborn pneuma" 8 which has to be sustained by external air. In the lungs the inhaled air is digested as food is in the liver. Through the pulmonary veins this product reaches the heart. Here as well as in the arteries it is further assimilated and transported to the various parts of the body. For special purposes, however, additional refinement is needed, above all for the nourishment of the psychic pneuma. The arteries of the rete mirabile serve this purpose which is realized in the ventricles of the brain?.

This picture of the seat and nourishment of the vital pneuma agrees with GaLen's description of the heart as "the principle of the entire life", 10 and the "home and fount of the innate heat by which the animal is supported"."11

${ }^{6}$ Galen, Methodus medendi, XII, ch. 5; ed. KüHN, vol. 10, p. 839f.: $\tau о \tilde{v} \mu \dot{\varepsilon} v \delta \dot{\eta} \psi v v \chi \varkappa o \widetilde{v}$

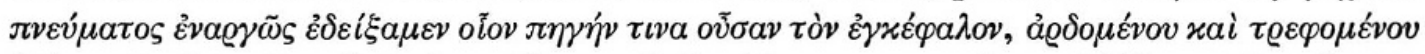

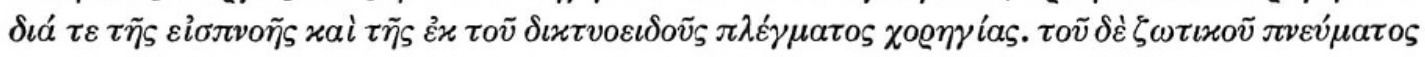

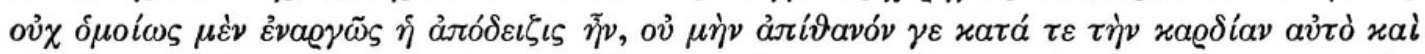

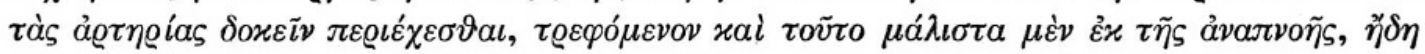

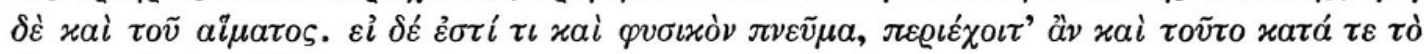

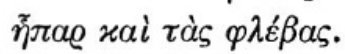

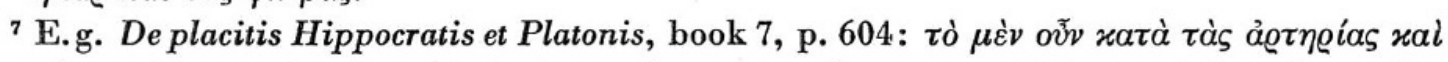

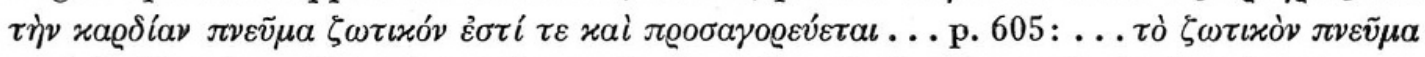

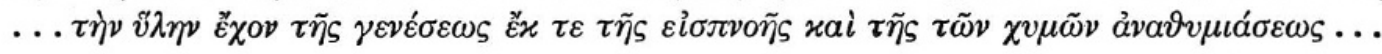

${ }^{8}$ De usu partium, rec. Georgius Helmreich, 2 vols., Lipsiae 1907-1909. See book 7,

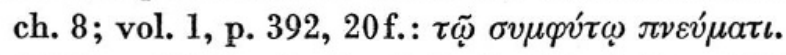

${ }^{9}$ Ibid., p. 393 f.; also book 9, ch. 4 (vol. 2 , p. 12 f.).

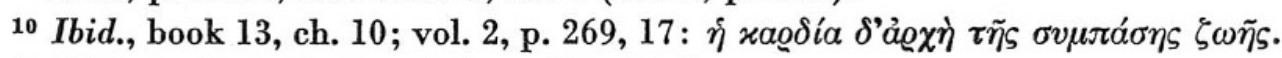

${ }^{11}$ Ibid., book 6, ch. 7; vol. 1, p. 318, 15-7. 
Moreover, it agrees with the then customary designation of the left ventricle as the "pneumatic cavity"12. Nor is it difficult to understand how the blood itself could also provide nourishment for the vital spirit. In his discussion with the followers of Erasistratus, Galen had made it abundantly clear that the arteries were not void of blood. And the arterial blood, as he did not tire of repeating, was fine and vaporous ${ }^{13}$; it could, therefore, easily nourish the vital spirit; GALEN even suggested that the psychic spirit was an exhalation from useful blood ${ }^{14}$.

But the discussion with the followers of Erasistratus also brought him to the point where the above picture becomes obscured. This sect argued that, under normal circumstances, the arteries contained nothing but pneuma, the blood being restricted to the veins. Only under pathological conditions did blood enter the arteries through anastomoses with the veins. In his attempt to prove that in health too the arteries carried blood, GALEN minimized the role of the pneuma in the arteries. Very little, if anything at all, of the inspired air reaches the heart, for we need a quality rather than a substance from the air ${ }^{15}$. Ligatures tied around the carotid arteries leave the animal breathing and moving, which proves that the brain is not in great need of the pneuma from the heart ${ }^{16}$. The psychic pneuma receives the bulk of its nourishment from respiration through the nose-an allusion to the theory of the ventilation of the anterior cerebral ventricles through an alleged communication with the nose ${ }^{17}$. Above all, in lesions of arteries no pneuma can be seen escaping. "As the blood in the arteries is relatively warm, so it is also relatively vaporous. However, no vapor, air, ether, or any pneuma at all appear to be contained in it as such."18 In other words, there is no free pneuma in the arteries but only an admixture in the arterial blood $^{19}$. It seems that in view of his own qualifications GALEN was right in

12 Ibid., p. 318, 20-2. Of course GALEN believed that the left ventricle contained blood too. 13 See below.

14 Ibid., book 6, ch. 17; vol. 1, p. 361, 17-8. He seems here to have in mind arterial blood.

15 An in arteriis natura sanguis contineatur, ch. 6 ; ed. KüHN, vol. 4, p. 725 ; De usu respira-

${ }_{16}$ De usu respirationis, ch. 5 , ibid., p. 503.

17 Ibid., p. 504 and De usu partium, book 8, ch. 10.

[tionis, ch. 3, ibid., p. 484.

${ }_{18}$ An in arteriis natura sanguis contineatur, ch. 2; ed. KüHN, vol. 4, p. 707. And yet he claimed that the superficial arteries near the skin attracted external air and he differentiated between pneuma, vapor, and refined blood; see On the natural faculties, book 3, ch. 14, ed. A. J. Brock (Loeb Classical Library), p. 316. See also below, note 36.

19 See J.Prendergast, Galen's view of the vascular system in relation to that of Harvey, Proc. Roy. Soc. Med., vol. 21, 1928, p. 1846. 
saying that the existence of a vital pneuma was not proved beyond doubt. Even if it was said that the pneumatic ingredient of the arterial blood constituted the vital pneuma, this ingredient was hardly a specific one, for the venous blood too contained pneuma.

On occasion GaLEN gives his reader the impression that the venous blood from the liver ist not supposed to contain pneuma at all, in contrast to the arterial blood from the left ventricle of the heart ${ }^{20}$. But such extreme formulations can be counterbalanced by many references which, in the aggregate, weaken considerably the difference between composition and function of the venous blood, on the one hand, and the arterial, on the other.

The veins serve the main purpose of anadosis, i. e. transportation of proper nourishment to the organs. The chyle from the gastrointestinal tract reaches the veins of the portal system where it appears as crude blood. The main process of hematopoiesis is effected in the liver, the supposed origin of the veins ${ }^{21}$, which now offer to each part what it will attract, hold, assimilate, and eliminate by means of the natural faculties. In addition, the veins contain pneuma from three main sources. In the first place, the veins take the vaporous and useful part of the winds developed in the abdomen ${ }^{22}$. In the second place, the juices of chyle and blood can and do exhale some pneuma, so that even the psychic pneuma, to a small extent, may be engendered from the veins in the cerebral ventricles ${ }^{23}$. This is of importance in as far as the pneumatic content of the venous blood can substitute for the vital pneuma of the arteries. At any rate, the blood in the veins to some extent is vaporous; for its "thinnest and most vaporous" portion is attracted by the arteries through their anastomoses with the veins ${ }^{24}$. The arterial blood in turn, through these anastomoses forms a third source of pneuma for the veins. "The arteries and veins form synastomoses in the whole body (i. e. where the walls of the two kinds of blood vessels border upon each other ${ }^{25}$ and accept from each other blood and pneuma through some invisible and perfectly narrow paths." ${ }^{26}$ The role which the pores in the intraventricular septum of the heart are supposed to play in this respect

${ }^{20}$ E. g. De placitis Hippocratis et Platonis, book 6, p. $566 f$.

${ }^{21}$ De usu partium, book 4, ch. 12.

22 Ibid., book 4, ch. 9; vol. 1, p. 214.

${ }^{23}$ De placitis Hippocratis et Platonis, book 3, p. 326, 4-6.

${ }^{24}$ On the natural faculties, book 3, ch. 14; ed. BRock, p. 316.

${ }^{25}$ De usu partium, book 6, ch. 17; vol. 1, p. 361, 2-5.

${ }^{26}$ Ibid., book 6, ch. 10; vol. 1, p. 332, 14-7. 
is too well known to need any comment. It is only necessary to add that in GaLEN's opinion the arteries which reach the intestines on their part also absorb a little food ${ }^{27}$ in order to see the far-reaching parallel between arterial and venous blood. Neither of the two is without a pneumatic ingredient; the difference is one of degree. Where as blood and pneuma are fine and thin in the arteries, they are crude and "smoky" in the veins. And whereas the arterial blood has a large pneumatic component, the latter is much smaller in the veins ${ }^{28}$. Just because the difference is only one of degree, both arteries and veins can supply the organs with food. Generally speaking, the organs take thinner food from the arteries, thicker food from the veins ${ }^{29}$. In particular, the nature of the organ will decide the kind of blood needed $^{30}$. The spongy spleen shows a wide ramification of large arteries and the lungs receive blood from the right ventricle of the heart where it has assumed an almost arterial character ${ }^{31}$. The liver, on the other hand, has small arteries chiefly for cooling purposes. They do not absorb blood from the liver, nor do they have to feed its tissues with thin and vaporous food, "nor do they have to furnish the liver with much vital pneuma as they do some other organs". ${ }^{2}$

With these last words we are back at the vital spirit and the implied contention that it is carried in the arteries. After what has been said we need not reiterate the difficulties inherent in GALEN's concept of the vital spirit; but we may well ask ourselves whether we have learned anything about a natural spirit. Is the latter identical with the pneumatic component of the venous blood? Perhaps. But in that case it would only be an inferior form of the pneuma contained in the arteries. Or as one might say, both veins and arteries carry blood mixed with natural spirit, but the veins have much blood and little vital spirit, whereas the arteries have little and purer blood, and more and thinner natural spirit. This indeed is stated in the pseudoGalenic Medical definitions ${ }^{33}$. But in the Galenic system a natural spirit, as

${ }^{27}$ On the natural faculties, book 3, chs. 13 (p. 308), 14 (p. 316f.), 15 (p. 318). De usu partium, book 4, ch. 17; vol. 1, p. 241, 25 f.

${ }^{28}$ See e. g. De usu partium, book 6, ch. 16; vol. 1, p. 358, 5-9.

${ }^{29}$ Ibid., book 4, ch. 15; vol. 1, p. 234, 3-8.

${ }^{30}$ Ibid., book 6, ch. 10; vol. 1, p. 328, $11 \mathrm{ff}$.

${ }^{31}$ Ibid., book 4, ch. 15. The arteries in the spleen also serve the additional function of altering the thick juice which the spleen receives from the liver through their pulsation and conveyance of heat from the heart.

32 Ibid., book 4, ch. 13; vol. 1, p. 225, 25 f.

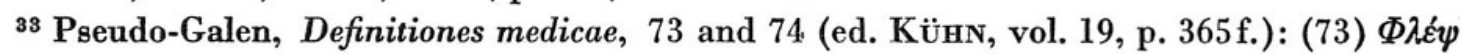


distinctly differentiated from the vital spirit, has little meaning. It has no specific function to fulfill, and, to the best of my knowledge, it is not mentioned in GaLEN's basic physiological works, viz. On the dogmas of Hippocrates and Plato, On the natural faculties, and On the use of parts. If this is true, we have to ask ourselves why GALEN mentioned the natural spirit at all, in view of his obvious doubts. To answer this question we have to return to the passage in the Method of treatment and interpret it in the context of the chapter in which it occurs.

In this chapter GALEN continues his discussion of syncope, which had been defined as an acute collapse of the faculties. The substance ${ }^{34}$ of our faculties consists in the pneuma and the temperament of the solids. GaLeN makes some general remarks about this substance in the light of disease and therapy. The substance of the pneuma and the solid parts have to be preserved so that they remain normal as far as possible in quality as well as quantity. However, the best one can do is to replace the loss of substance and to set aright a deviation from the well tempered condition. From such considerations GALEN is led to make the statement quoted above about the psychic, vital and natural spirits ${ }^{35}$. "However", he adds, "we have discussed at very great length the substance of the faculties in the (work) on the dogmas of Hippocrates and Plato." He now turns to the substance and temperament of the solid parts of the body, and then comes back to the pneuma. This, he says, canbe altered by vicious humors and the badness of the surrounding air, and besides by noxious potencies or the poison of venomous animals. The corruption of the substance of the pneuma can be due to psychic affection, severe pain, and too much movement (sleeplessness also belongs here), by exceeding thinness of the pneuma and porosity of the bodies containing it and, above all, by stoppage of breathing and want of food. All these demand careful correction. Psychic affections, in which the

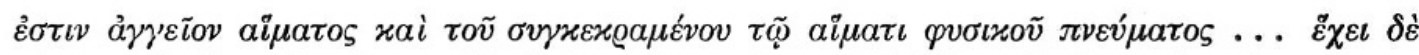

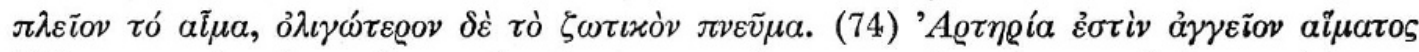

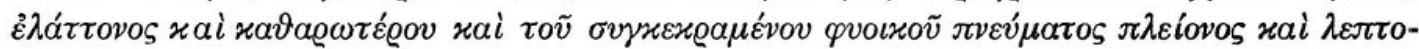

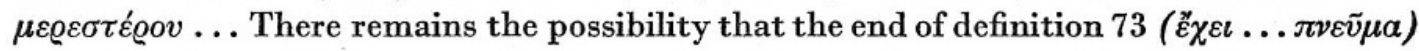
may be a gloss, added as a parallel to another definition (no. 74, p. 366) according to which the artery carries vital spirit from the heart. This second definition seems Erasistratean in character. If this is true, then nos. 73 and 74 are a mixture of pneumatic and Erasistratean concepts.

${ }^{34}$ Methodus medendi, book 12 , ch. 5 ; ed. KüHN, vol. 10, p. 837. $\dot{\eta}$ ov̉oía whereby GaLEN means the material substratum.

${ }^{35}$ See text and above, footnote 6 . 
soul moves itself, are: sudden and vehement fear as well as very great joy (if they do not kill, they can at least render the pneuma exhausted and weak), grief, anguish, anger, worry, and much sleeplessness. There are also the active functions where the soul moves the body-in either event immoderate movements weaken the strength of the soul. Excessive pain (or work ?) harms everybody. In all such cases the patients are weakened; some even die, be it that the pneuma is destroyed, be it that it is altered and sometimes partially dispersed-often both. The details of the manner by which damage is brought about, GALEN says, need not be gone into here, but the very fact of the damage is important for the preservation of strength in disease. When the substance of the spirits which control us is rarified beyond the normal, it becomes weak, altered in its temperament, and easily dispersed. In the same manner, if the whole body has changed to immoderate porousness, the substance of the spirits is easily dispersed since it is now composed of thin particles and since the body does not support it. Therefore, one must neither unduly rarify the body of the patient if one intends to keep the pneuma within it, nor must one vigorously attenuate the content of the body by what is eaten and drunk. Morever, one must not only heed food and drink but also pay attention to the temperament and purity of the inhaled air. (The rest of the chapter deals with the solids and with details in the treatment of syncope.)

From this paraphrase we hardly learn anything new about the nature of the vital or natural spirit. The references to air and respiration, humors, food and drink do not carry us beyond what we already know. Nevertheless, two things do stand out. There is, first of all, the fact that GALEN very often speaks of "the pneuma" in general and even where he uses the plural, "the spirits" are not specified. On the other hand, the detailed reference to psychic affections agrees very well with GALEN's assured opinion of the psychic spirit and, to a lesser degree, vital spirit too.

The existence of pneuma within the body as a requisite of animal life is a basic tenet of GALEN's biological and medical doctrine. Equally basic is the assumption of one specific category of the pneuma, viz. the psychic spirit. It is the indispensable organ of the rational soul and the medium by which the function of the senses as well as nerves can be explained. Once the psychic spirit is acknowledged as a category, the remaining pneuma must also be accounted for. Life depends on respiration. Thus a special vital spirit is connected with the respiratory organs which in GALEN's physiology include heart and arteries. But since the pneuma as such is really essential for life, 
the notion of a special vital spirit loses in clarity and GALEN wavers between dogmatic affirmation and vagueness. Any further specification is really unessential ${ }^{36}$. It may be that there are passages in GALEN's writings, preserved or lost, where he expresses himself more precisely about the natural spirit. At present I should like to make the following tentative suggestion. The term "natural spirit" was current at GALEN's time. Tradition even had it that the ancients had assumed two spirits, the psychic and the natural ${ }^{37}$. He himself believed in the existence of pneuma in the venous blood. Thus he mentioned the natural spirit as a possibility at least. If it existed it had to be assigned a center. The liver, as a compact organ, was not altogether a suitable seat for any pneumatic substance. However, it was the seat of the concupiscent soul and of the natural faculty ${ }^{38}$, and the origin of the veins. If a natural spirit existed, it should have its seat in the liver. But the canonization of the three spirits came later. The Alexandrians and their heirs, the Syro-Arabic physicians, found it necessary to simplify and concentrate the older doctrines, especially GaLen's profuse and often contradictory views. In the Isagoge of Joannitius ${ }^{39}$ (HUNAIN IBN IsHaQ) we read under the heading "De spiritibus": "Thus there are three spirits: fitst the natural which takes its origin from the liver; second the vital from the heart; and third the psychic from the brain. Of these the first is diffused

${ }^{36}$ GALEN can even contrast the psychic spirit with "all other spirits" (De usu partium, book 16, ch. 10; vol. 2, p. 420, 18/9). I do not believe that this refers necessarily to the vital and natural spirit since "pneuma" is a very general term. Even the stomach contains pneuma (Natural faculties, book 3, ch. 7, ed. Brock, p. 254). Although GALEN at times distinguishes between pneuma and vapor in the arteries (see ibid., book 3, ch. 15; p. 330), it is hard to tell where the distinguishing line should be drawn.

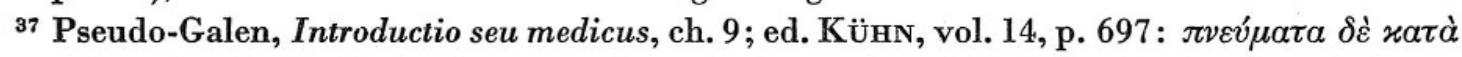

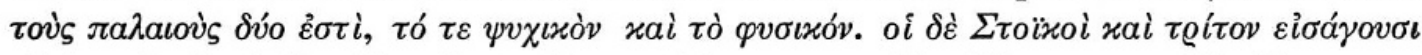

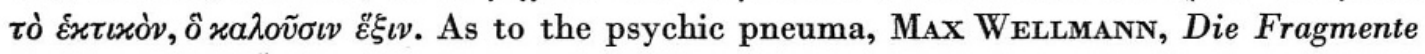
der sikelischen Arrzte etc., Berlin 1901, p. 137 (no. 44) and 142 (no. 59) gives two fragments in which Diocles of Carystus uses the term. Since the so-called Anonymus Parisinus is the doxographic source for these statements, WeRnER JAEGER, Diokles von Karystos, Berlin 1938, p. 215, has suggested that the term $\psi v \chi \iota x o ̀ v ~ \pi v \varepsilon \tilde{v} \mu \alpha$ may be due to later usage. With regard to Hippocratic works, such a reinterpretation can be proved. Thus in the discussion of epilepsy the ANONYMus makes the author of On the sacred disease speak of the psychic pneuma where the latter merely refers to inhaled air; cf. O.TeMKIN, Epilepsy in an anonymous Greek work on acute and chronic diseases, Bull. Hist. Med., vol. 4, 1936, p. 143.

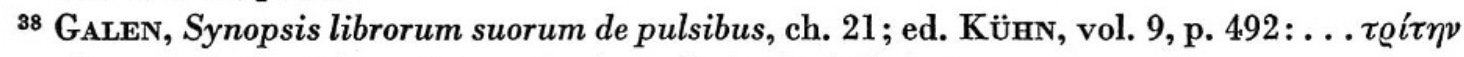

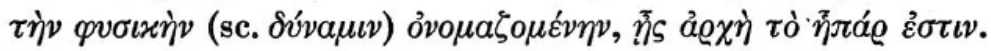

39 I have used the text of the Articella, ed. Venice, 1491. 
from the liver over the whole body through the veins which have no pulse. The second is directed from the heart into the whole body by the arteries. And the third is directed from the brain into the wholebody by thenerves..." Here indeed we have the complete triadic formula as a theoretical axiom of medecine.

Our discussion of Galen's pneumatology, brief as it is, may yet allow us to end on a more general note. In the course of our analysis we have assembled passages which show GaLEN's opinions under different and divergent aspects. The mere fact that this can be done demonstrates the relative weakness of systematic concentration in GALEN's writings. GALEN has pronounced views to which he clings persistently. But it was in the philosophical and dialectic nature of ancient science that details were often worked out in argumentation against views of others. GALEN's emphasis shifted according to the point he wished to make or the view he wished to combat. This does not mean that the niceties of his opinions cannot possibly be reconciled. But it does mean that such reconciliation, if attempted, needs elaborate interpretation. Thus the Galenic "system" of the late Alexandrian commentators and their heirs arises side by side with the Aristotelian systems of their philosophical colleagues ${ }^{40}$. The endurance of this scholastic interpretation speaks best for its quality, but it also has to be taken into account in our approach to GALEN's thought.

${ }^{40}$ For the parallel activities of Aristotelian and Galenic commentators in late Alexandria see O.Temкin, Geschichte des Hippokratismus im ausgehenden Altertum, Kyklos, vol.4, 1932 , p. 43. I mention this parallel here again because the question arises whether divergent views in GaLeN's works can be explained by a development similar to the one shown for Aristotle by Werner Jaeger. In some important matter Galen did change his opinions, for instance with regard to the temporal relationship of liver and heart in embryological development (GALEN, De foetuum formatione libellus, ch. 3; ed. KüHN, vol. 4, p. 662). Many more examples of this sort could undoubtedly be found in his works. On the other hand, his works are too well interconnected to make an explanation of all divergencies on this basis likely. 